\title{
A CONTRASTIVE ANALYSIS OF RELATIVE CLAUSE GRAMMAR IN BOTH ARABIC AND ENGLISH
}

\author{
Rana Abid THYAB ${ }^{1}$
}

\section{Istanbul / Türkiye \\ p. 231-237}

Received: $02 / 12 / 2021$

Accepted: $18 / 12 / 2021$

Published: 01/01/2022

This article has been scanned $l$ iThenticat No plagiarism detected

\begin{abstract}
:
As with any language learning process, learning English relative clauses is not an easy task for a number of reasons. Moreover, learning relative clauses by English language learners whose mother-tongue is Arabic is faced with difficulty for many. Learners of English relative clauses, with an Arabic first language, come across areas of similarity and difference regarding rule formation in both English and Arabic. These similarities and differences could be a major source of positive and negative transfer. Also, known within contrastive studies and error analysis. This paper supports and highlights such limited findings. Arabic mothertongue learners of English encounter difficulties in their use of the English relative clauses because of negative transfer. The Arabic language has relative clause formation rules that function both similarly to English, in parts, and differently, in other parts. Thus, notions which are encoded differently than in that of the English language is found to cause noticeable mistakes and errors by learners. Given the fact that relative clauses are one of the most frequent grammatical structures used in the English language, as well as in Arabic, this paper has aimed to pin down such an important issue. The aim of this paper is to pinpoint limited findings and limited studies regarding English relative clauses' use by Arabic native speakers. This is done by illustrating how the differences between the Arabic and English languages in concern to relative clauses' formation rules cause learners of English with an Arabic mother-tongue to make repeatable mistakes and errors in their English learning process, specifically with regard to relative clause grammar and formation rules.
\end{abstract}

Key words: Relative Clauses, Transfer, Mother-Tongue. 


\section{Introduction}

Language has an interactive function because it is used to communicate. Language allows us to perform speech acts and to have an expressive effect. This study aims to discuss two different languages: English and Arabic. Within this study the focus is on English and Arabic relative clauses. (Diagne, S. \& Faye, J. C., 2021)

Within the English language, a relative pronoun is considered as a group of words which replace nouns or other pronouns which are derived from (Wh-) such as: who, which, whose, whom, and whose. A relative pronoun in English introduces a clause or a part of a sentence which describes a noun. (Ibid)

Relative clauses' formation in both the English and the Arabic language are somewhat similar in many constructions. Nonetheless, there are certain distinct aspects which cause mother-tongue interference and a place for error and mistakes. (Hamdallah R.W. \& Tusheyeh H. Y., 2019)

within this paper a contrastive study will be implemented to investigate areas of comparison and contrast between English and Standard Arabic relative clauses to also investigate areas of mother-tongue interference.

The treatment, here in this paper, of the relative clauses is an analysis in the generation of English relative clauses and an examination of how the rules of derivation of these clauses in Standard Arabic interact with the application of English relative clauses. Analysis, here, is of surface structure similarities and differences between the two languages. This, hopefully is attempted to be done, in the aim of identifying areas which pose problems for Arabic speakers in learning to produce English relative clauses.

\section{Literature Review}

English language learners encounter a number of difficulties when it comes to learning English. Moreover, when it comes to forming relative clauses, problematic issues arise due to differences between languages, as well as the nature of the English language regarding relitivization. Mother-tongue interference with concern to relitivization is also a source of difficulty, mistakes and error. Before moving more deeply, mother-tongue interference means the effect of the learner's native language on second/foreign language learning.

Mother-tongue is one's native language, first language or parent language. (The Free Dictionary, 2015)

Mother-tongue interference refers to the effect of the learner's first language (L1) on her/his acquisition of the target language. The target language, in turn, is the language the learner is aiming to learn (L2). (Contrastive Analysis, 2015)

Problems of mother-tongue interference come about when learning a new language whether English or otherwise. One of these problems is mother-tongue interference in the acquisition of the English relative clauses.

Contrastive Analysis examines different languages with the aim of discovering their structural similarities and differences. Contrastive Analysis is a method that was greatly used in the 1960s and 1970s to explain reasons behind new language learning difficulties and reasons why some features of a target language were more difficult to learn than others. (Mozlan, 2015)

The basis within this method is that the more difference between the learners' mothertongue and the target language, the more difficulty the learner will come across when learning the target language structures and features. (Contrastive Analysis, 2015)

It was suggested in (Cantrative Analysis Hypothesis (CAH)) that difficulties faced with learning a new language could be predicted depending on the degree of difference between the learner's first language and second/foreign language. Nevertheless, there are certain problems with this hypothesis, for instance, this hypothesis does not predict many of the errors and mistakes that the learner makes in second language learning. Another problem is that this hypothesis predicts interference errors and mistakes where they, in fact, do not ascend. (Eric, 2008)

It was asserted by Lado that those items of a target language that are similar to the learner's native language would be easy for her/him to learn. Whereas, those features of a 
target language that are different from the learner's native language would be difficult for the learner to learn. This is the basis of what the Contrastive Analysis Hypothesis suggests. (Lado, 1957)

The Contrastive Analysis Hypothesis (CAH) has two versions. One is known as the strong version and the other as the weak version. The strong version claims that the number of errors a learner of a target language will come upon could be equated to the degree of difference between the learner's native and target language. The weak version asserts that errors a leaner of a target language encounters depends on the degree of mother-tongue interference a learner face. (Contrastive Analysis Hypothesis (CAH))

Arabic speaking learners of English tend to make errors when they try to form relative clauses in English as a Second/ Foreign Language (ESL/EFL). Some of these errors are attributed to the difference between relitivization in both Arabic and English. I.e., these errors are made due to the interference of the learner's mother-tongue (Arabic) on the learner's target language (English). Interference of the mother-tongue is also known as "Transfer". Transfer defined as the effect of the learner's first language upon the learner's target language. It is important to mention, though, that there are two types of transfer, in language learning. (Sabbah, 2015)

According to Sabbah, nevertheless, transfer is of two types. There is both positive transfer and negative transfer. Positive transfer refers to the process of using rules from the learner's mother-tongue which facilitates or has a positive influence on learning the target language. This transfer is mostly due to similarities between the learner's first language and target language. In contrast, negative transfer is the transfer of rules from the learner's mother-tongue which impedes or has harmful influence on the command of rules of target language This is due to differences between the first and second/foreign language. (Ibid)

Errors in language learning can be explained by referring to language learning theories. Among these theories are the Contrastive Analysis Theory and the Error Analysis Theory. The Contrastive Analysis Theory is used to explain a language learner's errors. Contrastive Analysis studies the similarities and differences between two languages or more asserting to the claim that learners will tend to refer back to their native language when they encounter target language items that greatly differ from their native language. The second theory of language learning is "Error Analysis", which studies learners' errors in the target language with the aim of recognizing the reasons behind such errors and their causes.

\section{Definition of Relative Clauses}

A relative clause, according to transformational grammar, is a surface structure of an embedded sentence that's is formed following a definite or an indefinite head noun phrase named the antecedent. (Hamdallah R.W. \& Tusheyeh H. Y., 2019)

The antecedent is who or what a sentence is talking about and relative clauses either help to clarify the antecedent or give extra information about it. (Diagne, S. \& Faye, J. C., 2021)

Relative clauses could be adnominal clauses which are considered central types of relative clauses. The antecedent of adnominal relative clauses form part of the main clause. Nonetheless, nominal relative clauses have its antecedent. Sentential and nominal relative clauses are also adnominal clauses but are briefly discussed. In the sentential relative clause, the antecedent is the complete clause. Whereas restrictive relative clauses are connected with the antecedent and as they give essential information for the identification of the antecedent which they modify, non-restrictive relative clauses have a weak relation with the antecedent they modify. Non-restrictive relative clauses are also known as parenthetic or descriptive relative clauses and they give additional and non-essential information about the antecedent which they modify. (Ibid)

When forming the relative clause, the rule asserts the deletion of the second identical noun phrase. That is, the noun phrase of the embedded sentence. The rule acquires the replacement of the second identical noun phrase by the appropriate relative pronoun. Here, the relative clause formation rule is similar to its rule in Standard Arabic. That is, the relative clause is always placed after the antecedent. Yet, there is a small difference between both languages concerning the relative pronoun. Within the English language, the relative 
pronoun may come after either a definite antecedent or an indefinite antecedent. For example:

1. The girl who was swimming fast stopped.

2. A girl who was swimming fast stopped

In Standard Arabic, however, relative pronouns do not follow an idefinte antecedent. Thus, while example (3) in Arabic is correct, example (4) is not.

3. I saw the man who lost.

رأيت الرجل الذي خسر

4. I saw a man who lost.

رأيت رجلا الذي خسر

\section{Relative Pronouns in both Arabic and English}

In English, there are five forms of the relative pronoun which are: who, whom, whose, which, and that. Relative pronouns, in Standard Arabic, have the same base but with phonological differences in masculine and feminine and different endings for case and number. That is, in Standard Arabic, the relative pronoun is determined by gender, number, and case. In Standard Arab, these forms are not distinct as they are in English. Therefore, there are eight various relative pronouns in Standard Arabic. These forms are: الذي، التي، اللذان، (Hamdallah R.W. \& Tusheyeh H. Y., 2019)

However, in Standard Arabic, unlike in English, the relative pronoun does not take the place of a subject or object. Instead, it acts as an adjective and agrees with the antecedent in gender, number, and case. (Ibid)

Moreover, a basic difference between Standard Arabic and English in relativization is that in Standard Arabic there is an appearance of a personal pronoun in the relativized site called (الضميرالعائد) which agrees with the relativized noun phrase in number, gender, and case. In English, nonetheless, there is no such pronoun. (Hamdallah R.W. \& Tusheyeh H. Y., 2019)

For example: "الفتاة التي سافر أبوها اسمها هبة" أو "الرجل الذي أحمد أطول منه فاز"

As well, there are restrictive and non-restrictive relative clauses in both English and Arabic. In both English and Standard Arabic, non-restrictive relative clauses are surface structure realizations of a conjoined sentence immediately preceded by a noun phrase. This noun phrase has a reference that is unique to both speaker and hearer and contains a noun phrase that is referential with a specified antecedent. Similar to non-restrictive relative clauses in English, non- restrictive relative clauses in Standard Arabic are derived from conjoined sentences. (Ibid)

Furthermore, both in English and Arabic, there are nominal and verbal relative clauses. In nominal sentences, the predicate is either an adjective or a prepositional phrase. Also, both in English and Arabic, there are two types of relativization: object and subject. Object relativization is the relativization of the direct object, the indirect object or the object of a preposition. As, for example: "الكتاب الذي قرأت" meaning "The book which I read".

In English, as in Standard Arabic, there are free or headless relative clauses as in the example: "من يدرس ينجح" which is translated into "He who studies succeeds"

As stated above, relative clauses in English and Standard Arabic are formed in similar ways in many constructions. Nevertheless, there are distinct aspect between both languages. Relative clauses' formation process is basically the same in English and Standard Arabic. English has, for instance, five different forms of relative pronouns.

Standard Arabic, on the other hand, has eight different relative pronouns. The relative pronoun in Standard Arabic, unlike in English, agrees with the antecedent in number, gender, and case.as well, in Standard Arabic, the relative pronoun appears with definite antecedents only. Furthermore, there is a basic difference between relative clauses, in both English and Arabic. This basic difference is appearance of a personal pronoun in the relativized site. This pronoun, known in Standard Arabic as (الضمير العائد) agrees with the antecedent in gender, number and case. English relative clauses and Arabic relative clauses could be formed as both restrictive and non-restrictive clauses, nominal and verbal relatives, subject and object relatives and free or headless relative clauses. That is, English 
and Standard Arabic relative clauses are similar in many forms, however, there are slight differences between English and Standard Arabic in this respect. (Hamdallah R.W. \& Tusheyeh H. Y., 2019)

From the above rules regarding relative clauses, it is found that there are areas where the process of relativization in both English and Standard Arabic are similar. For instance, in both English and Standard Arabic relative clauses are identical in function and in distribution. In both languages relative clauses are derived by embedding a sentence in a noun phrase as a modifier if the embedded sentence contains a noun phrase and only if this noun phrase be identical with the noun phrase it serves as modifier. Nevertheless, there are differences between the two languages despite the similarities. For instance, despite the apparent similarities, differences between the two systems regarding relativization appear even within this correspondence. (Hadra, 1978)

In English, for instance, the shared noun phrase which is in the embedded sentence (whether subject or object) is replaced by an acceptable relative pronoun which is itself governed by certain restrictions. In Standard Arabic, unlike English, the shared noun in the embedded sentence is deleted and left with no pronoun in its place when the noun in the relative clause is subject of the clause. For example, "الرجل الذي قابلني "translated into " The man the met me", instead of "The man who me" which is correct English. Also, for instance, the example "رجل قابلني translated as "Man met me" instead of the correct English relative clause "A man who met me". In such sentences, it is found that mother-tongue interference and first language negative transfer appears obvious and clear. This is because the rule in Standard Arabic suggests that when the relativized noun phrase is subject of the relative clause, the duplicate embedded noun is deleted. The rule in Standard Arabic, unlike English, also leaves a zero pronoun when it is non-subject of the relative clause. In Standard Arabic, the relativization rule states the deletion of the identical embedded noun in the relative clause. As in, for example, in Arabic, it is correct to say "الرجل الذي قابلته البارحة" which is translated as "The man that I met him yesterday" instead of the correct English sentence "The man (whom) I met yesterday". Another example includes the Arabic sentence "رجل قابلته البارحة" which could be incorrectly translated as "Man I met him yesterday" instead of a correct English relative clause sentence "A man whom I met yesterday". This is a further illustration of mother-tongue interference and error or mistake due to first language negative transfer despite similarities between English and Arabic relative clauses. These errors or mistakes occur if an English language learner of an Arabic native language attempted to rely on her/his mother-tongue to solve difficulties she/he might face when dealing with relative clause formation. (Ibid)

\section{Results}

Learning English Relative clauses, by students whose mother-tongue is Arabic can also be asserted to the significance of the Contrastive Analysis Hypothesis, similar to other grammatical structures in English. This paper backs and highlights such findings. Due to similarities and differences between the rules of Arabic relative clause formation and English relative clause formation rules we find that Contrastive Analysis has a role to play in such structures. Many Arabic first language learners of English may encounter difficulties while trying to learn the correct use of relative clauses in English language and may commit many repeated mistakes and errors influenced by their mother-tongue and due to first language interference. The difficulty in learning English relative clauses faced by L2 English learners whose native language has both similar and dissimilar relative clause formation rules can cause English learners' confusion. According to Error Analysis and Contrastive studies, Arabic mother-tongue learners of English may refer back to their native language when dealing with relative clauses. Similarities between the two languages could be a helpful tool in grammatical rules which are similar but are a source of repeatable mistakes in parts which are different. That is because the Arabic language encodes the notion of relitivization in a similar way to English could be a source of equivalent error because learners of English may assume that dissimilar rules are in fact identical and be a source for implementing the Arabic rule formation of relative clauses in rules that apply different ways than that of the English language. Because of the uniqueness of the English relative clause formation rule system, Arabic L1 learners of the English language face significant difficulties in learning English relative clauses. Given the fact that relative clauses are one of the most frequent structures used in the English language, this paper has aimed to discuss such an important matter. 
The aim of this paper is to pinpoint Contrastive Analysis findings regarding English relative clauses, clarifying how the similarities and differences between the Arabic and English languages in concern to relative clause formation rules could lead Arabic native learners of English to make repeatable errors in their English learning process. These mistakes or errors are unconsciously or involuntarily made by Arabic native learners of English due to the differences between the relative clause rules in the two languages. These errors are made because of ignorance of the correct rule or structure, are made repeatedly and cannot be recognized by the learner of the target language. These errors are problems in the learner's knowledge of the target language. Such contrastive errors are considered gaps in the learner's competence or knowledge.

\section{Discussion}

Errors and mistakes due to first language interference is made in relative clauses when students of an Arabic mother-tongue aim to translate relative pronouns from Arabic into English. Due to similarities between both English and Arabic relative clauses, English language learners may attempt to refer back to their native language in order to support English second/foreign performance regarding relative clauses.

Making mistakes and errors during the journey of new language learning is something inevitable, nevertheless, errors should lead to improvement, progress and not lead to frustration. As well, teachers should learn how and when to correct these errors. The suggestion, here, to teachers of second/ foreign language classrooms is to show respect to the learners' native language and that teachers highlight areas where the native language would be a source of error, if the teacher was knowledgeable of the learners' native language. This, in turn, should help learners of the English language to overcome such problems and lead to better target language acquisition.

\section{Methods}

A qualitative approach has been followed in this paper through the study of previous case studies, and accomplished researches. Within this paper analysis has depended on the study and analysis of pre-existing data as well as through the comparison between Arabic and English relative clause formation rules. Certain cases, within this paper, are observed and based according to Contrastive studies and Contrastive Analysis theories and thus a thorough analysis of data has been reached.

\section{Conclusion}

This paper concludes that learning English relative clauses by learners whose mothertongue is Arabic emphasizes the importance of Contrastive Analysis. This is due to the fact that Arabic native speakers encounter noticeable difficulty while attempting to use English relative clauses. The source of such difficulty is based on the degree of similarity and difference between relative clause formation rules in Arabic and the English.

The difficulty in learning English relative clauses by Arabic natives is because their native language has relative clause formation rules that functions both similarly and differently. Areas of similarity is found to lead to positive transfer from the mother-tongue into English. Similarity; however, can be a huge source of error, because learners of English tend to refer back to their mother-tongue in most relative clause formation rules. Furthermore, formation rules, which learners find difficulty in learning could be a major source of error. Similarity between both English and Arabic relative clauses is found to mislead learners of English to overgeneralize Arabic relative clause rules. Learners, thus, apply and mistranslate these Arabic relative clause rules into English in aim to solve difficulties in English relative clause formation rules. 


\section{References}

Al-Lami, M. (2006) "Assessing EFL Students' Cultural Awareness of the English Language," Dissertation Univ. of Baghdad, 1-25.

Contrastive Analysis. (June 17, 2015). Wikipedia. Retrieved from https://en.wikipedia.org/wiki/Contrastive_analysis

Contrastive Analysis Hypothesis (CAH). Retrieved from csuni.edu website https://www.csun.edu/ ghagopian/Documents/CAHContrastiveAnalysisHypot heses.pdf

Diagne, S. \& Faye, J.C. (2021). A Contrastive Study of Relative Pronouns: The Case of WhConstructions in English and U-Constructions in Wolof. Himalayan Journal of Humanities and Cultural Studies, 2 (2).

https://himjournals.com/articles/141_A_Contrastive_Study_of_Relative_Pronouns_The_Cas e_of_WH_Constructions_in_English_and_U_Constructions_in_Wolof

Eric. (April 23, 2008). Contrastive Analysis Hypothesis. [Web log comment]. Retrieved from

http:/ / embruner.blogspot.com/2008/04/contrastive-analysis-hypothesis.html

Fromkin, V., Rodman, R. \& Hyms, N. (2003). An Introduction to Language. United States: Heinle Thomson Corporation.

Hadra, T. O. (1978). The Relative Clause in English and Sudanese Spoken Arabic: A Contrastive Analysis, 59, 24-46.

https: / /www.jstor.org/stable/44947532

Hamdallah, R.W. \& Tushyeh, H.Y. (2019). A Contrastive Analysis of English and Arabic in Relativization. Papers and Studies in Contrastive Linguistics 34, 141-152.

https:/ / sharifling.files.wordpress.com/2019/02/1.-a-contrastive-analysis-of-english-andarabic-in-relativization.pdf

Hassan, M. (2011). Acquisition of English Articles by L1 Arabic Speakers. Universiti Putra Malaysia, 1-214

http://psasir.upm.edu.my/20076/1/FBMK_2011_24_ir.pdf

Hudson, R.A. (1556). Sociolinguistics. Great Britain: Cambridge University Press.

Lado, R. (1957). Linguistics Across Cultures. Michigan: University of Michigan Press.

Mazlan, A. (2015). Contrastive Analysis Theory. Sribd.com. Retrieved from http: / / ar.scribd.com/doc/129396815/Contrastive-Analysis-Theory\#

Mother Tongue. (2015). The Free Dictionary. Retrieved from http:/ /www.thefreedictionary.com/mother+tongue

Sabbah, S. (2015). Negative Transfer: Arabic Language Interference to English Learning. Arab World English Journal, 4, 269-288 http://www.academia.edu/12680728/Negative_Transfer_Arabic_Language_Inter ference_to_Learning_English 